Original paper

\title{
The effect of curcumin and exercise rehabilitation on liver paraoxonase- 1 and NF-k $\beta$ gene expression in the rat induced by forced drinking of ethanol
}

\author{
Hoseyn Fatolahi, Mohamad Ali Azarbayjani, Maghsoud Peeri, Hasan Matinhomaei \\ Department of Exercise Physiology, Central Tehran Branch, Islamic Azad University, Tehran, Iran
}

\begin{abstract}
Aim of the study: Binge ethanol drinking causes liver damage and decreased paraoxonase-1 (PON-1) gene expression. On the other hand, regular physical activity and curcumin consumption as non-invasive interventions can have liver protective effects through enhancing antioxidant defense, and improving PON-1 and NF-k $\beta$ (nuclear factor kappa B) gene expression. The aim of this study was to investigate the interactive effect of exercise rehabilitation and curcumin consumption on hepatocyte damage as well as NF-k $\beta$ and PON-1 gene expression in rats.

Material and methods: Fifty-six male Wistar rats were randomly selected and equally divided into seven groups: dextrose-control (Dext-Con), ethanol-control (Eth-Con), ethanol-saline (Eth-sal), ethanol-DMSO (Eth-DMSO), ethanol-curcumin (Eth-Cur), ethanol-swimming training (Eth-SWT) and ethanol-SWT + curcumin (Eth-SWT + Cur). After four days of the binge drinking protocol followed by six days of quitting, the interventions of SWT and curcumin $(50 \mathrm{mg} / \mathrm{kg}$ ) were employed for 14 days. Afterwards, the rats' liver tissues were collected and sent to the laboratory for biochemical assays.

Results: The interaction of SWT and curcumin caused an increase in PON-1 gene expression ( $p=0.02)$. In addition, curcumin consumption $(p=0.003)$ and its interaction with SWT $(p=0.004)$ resulted in a reduction in $\mathrm{NF}-\mathrm{k} \beta$ gene expression. Also, liver tissue damage was observed in the Eth-Con group compared to other groups. Conclusions: The combination of curcumin and SWT may be used to reduce the side effects of binge ethanol drinking and improve recovery in the quitting period.
\end{abstract}

Key words: herbal medicine, liver damage, turmeric, alcohol exposure, exercise rehabilitation.

Address for correspondence

Prof. Mohamad Ali Azarbayjani, Department of Exercise Physiology, Central Tehran Branch, Islamic Azad University, Tehran, Iran, e-mail: m_azarbayjani@iauctb.ac.ir

\section{Introduction}

A sedentary lifestyle and the growth of inappropriate behaviors including ethanol drinking have developed in today's societies. Alcohol consumption is known as one of the top causes of death by increasing the chance of chronic diseases [1]. Ethanol is also associated with increased hepatic damage, lipid peroxidation, atherosclerosis, and metabolic syndromes, especially dyslipidemia $[2,3]$. The most notable impact of ethanol, especially binge drinking, is the elevation of free radicals and the development of oxidative stress $[2,3]$. Over time, ethanol-induced damage may be im- proved; however, finding ways to enhance the recovery and improve the hepatic damage faster is necessary. Some of these methods include regular physical activity and the use of herbal anti-inflammatory compounds.

Studies have shown that performing regular exercise leads to positive effects on lipid profile including elevated high-density lipoprotein (HDL-C) $[4,5]$. Elevation of HDL-C, in turn, results in increased antioxidant properties and prevents LDL-C oxidation $[4,5]$. The antioxidant and anti-inflammatory properties of HDL-Care associated with paraoxonase-1 (PON-1) [6]. Previous findings have also indicated that physical activity has a positive effect on PON-1 [7-9]. As PON-1 
Table 1. Timeline of investigation (24 days) *

\begin{tabular}{lccccc}
\hline Groups & & $\begin{array}{c}\text { 1. Ethanol } \\
\text { induction }\end{array}$ & $\begin{array}{c}\text { 2. } \\
\text { Quitting }\end{array}$ & $\begin{array}{c}\text { 3. Inter- } \\
\text { ventions }\end{array}$ & $\begin{array}{c}4 . \\
\text { Sacrifice }\end{array}$ \\
\hline Dextrose & Con & DG &,--- SD &,--- SD & SC \\
\hline $\begin{array}{l}\text { Binge } \\
\text { ethanol } \\
\text { induction }\end{array}$ & Con & EG &,--- SD &,--- SD & SC \\
\cline { 2 - 6 } & Sal & EG &,--- SD & Sal, SD & SC \\
\cline { 2 - 6 } & DMSO & EG &,--- SD & DMSO, SD & SC \\
\cline { 2 - 6 } & Cur & EG &,--- SD & Cur, SD & SC \\
\cline { 2 - 6 } & SWT & EG &,--- SD & SWT, SD & SC \\
\cline { 2 - 6 } & Cur \& SWT & EG &,-- SD & Cur \& SWT, SD & SC \\
\hline & 4 days & 6 days & 14 days & $48 \mathrm{~h} \mathrm{later}$ \\
\hline
\end{tabular}

*..- - lack of interventions, SWT - swimming training, SD - standard diet, DG - dextrose gavage, $\mathrm{EG}$ - ethanol gavage, SC - sample collection

is produced in the liver, ethanol drinking decreases the PON-1 gene expression due to hepatic damage, which is a precursor for the incidence of hepatic diseases, diabetes, obesity, atherosclerosis, increased lipid peroxidation, and dyslipidemia [7-10].

The anti-inflammatory compounds present in herbal medicines are also effective in removing the complications of ethanol consumption. One of these plants is turmeric, with its active ingredient curcumin, which is especially effective in mitigating hepatic damage, improving lipid profile, and enhancing PON-1 gene expression; but the most important role of curcumin is in oxidative stress [11,12]. It should be noted that curcumin inhibits the nuclear factor kappa B (NF-k $\beta$ ) signal pathways and enhances oxidant defense, thus leading to reduced hepatic damage from ethanol consumption $[13,14]$.

The existing studies have not specifically dealt with the investigation of the interactive effect of specific exercises such as swimming. There is also a gap in studying the prescription of curcumin within a shorter period for measuring hepatic damage and changes in PON-1 gene expression following binge ethanol drinking. The non-invasive methods are also very valuable. Therefore, the aim of this study is to investigate the interactive effect of swim training (SWT) and curcumin consumption on PON-1 and NF-k $\beta$ gene expression following binge ethanol drinking in male Wistar rats. It is aimed to examine the effect of the combination of these two agents on the length of the treatment period and the durability of the effects following ethanol elimination.

\section{Material and methods}

\section{Permissions}

The whole experimental protocol in this study was approved by the ethics committee of Islamic Azad Uni- versity, Central Tehran Branch (No. 10121404942042) and was done in accordance with the NIH (National Institutes of Health) guide for the care and use of laboratory animals (No. 80-23), which emphasized the use of minimal animals being sacrificed and minimal pain imposed during the study.

\section{Animals}

Fifty-six male Wistar rats (200-250 g) which were capable of swimming were randomly selected and equally divided into seven groups: dextrose-control (Dext-Con), ethanol-control (Eth-Con), ethanol-saline (Eth-sal), ethanol-dimethyl sulfoxide (DMSO) (Eth-DMSO), ethanol-curcumin (Eth-Cur), ethanol-swimming training (Eth-SWT) and ethanol-SWT + curcumin (Eth-SWT + Cur) (Table 1). To evaluate the effect of curcumin, the results were compared with the group injected with normal saline. In addition, the DMSO group was used to evaluate the effect of DMSO alone (curcumin dissolved in DMSO). The animals were kept in a cage with constant temperature $\left(21 \pm 2^{\circ} \mathrm{C}\right)$, humidity (40-60\%), and 12/12 light-dark cycle (light was on at 7:00 a.m.).

\section{Binge ethanol induction}

The binge ethanol drinking protocol was induced by intragastric gavage every $8 \mathrm{~h}$ for 4 days (12 doses in total) in accordance with previous methods [15]. The animals were gavaged with an ethanol diet $(25 \%$ ethanol w/v in vanilla Ensure; Abbot Laboratories, Columbus, $\mathrm{OH}$ ) or an isocaloric control diet (dextrose in vanilla Ensure). This initial dose for each animal was $5 \mathrm{~g} / \mathrm{kg}$. The subsequent doses were administered depending on the behavior of ethanol up to a maximum of $7.4 \mathrm{~g} / \mathrm{kg}$. To ensure the isocaloric control diet, rations were cut for all groups in the binge ethanol drinking protocol. After binge ethanol drinking was induced, the diet changed to the standard and the animals were kept for 6 days without any intervention.

\section{Curcumin preparation}

Curcumin (Sigma, St. Louis, Mo, USA) was mixed with $10 \mathrm{mg} / \mathrm{ml}$ curcumin solvent (dimethyl sulfoxide: DMSO, Sigma, ST. Louis, MO, USA). The dissolved curcumin $(50 \mathrm{mg} / \mathrm{kg})$ was injected intraperitoneally for 2 weeks (five times per week, the same as swimming sessions).

\section{Swimming training}

The swimming training was performed 5 times per week for 2 weeks (at 11:00 a.m.). The training was 
performed in a large water tank (with a diameter of $150 \mathrm{~cm}$ ) at $32 \pm 1^{\circ} \mathrm{C}$, filled to a depth of $50 \mathrm{~cm}$. Each session of the SWT program began with $20 \mathrm{~min}$ and it was increased to an hour (until exhaustion) from beginning to end of interventions. Since the rats are more active at night, but exercises were done during the days, it was finally decided to perform the swimming in a dark room. After each SWT session, the animals were dried with a towel and returned to their cages.

\section{Biochemical assays}

To sacrifice the animals, they were anesthetized with a mixture of ketamine and xylazine (100 and $10 \mathrm{mg} / \mathrm{kg}$, respectively). To investigate gene expression, all samples were taken from the liver $(100 \mathrm{mg})$ and then frozen with nitrogen. Eventually the tissues were stored at $-80^{\circ} \mathrm{C}$. For histopathological investigations, the liver tissue was kept in formalin 10\%. All histological studies were conducted by the hematoxylin-eosin (H\&E) method and mason trichrome method for fibrosis assessment, and then the imaging and evaluating were conducted by Image J software.

To perform RNA extraction, a special kit was used (Qiagen, Hilden, Germany: QIAzol Lysis Reagent). RNA concentration was measured (Eppendorf, Germany) with a desired purification of 260 to 280 between 1.8 and 2. Creation of cDNA was also performed using a special kit (QuantiTect Reverse Transcription kit: Qiagen). The created cDNA was kept at $-20^{\circ} \mathrm{C}$ to be used for real-time PCR reactions. To measure gene expression, the realtime PCR quantitative method was applied, using Primix SYBR Green II (Applied Biosyste$\mathrm{ms}$, Step One, USA). The reactions and their combined experiments (final volume of $20 \mu \mathrm{l}$ ) (consisting of $1 \mu \mathrm{l}$ of cDNA, $1 \mu$ of forward primer, $1 \mu$ of reverse primer, $7 \mu \mathrm{l}$ of DEPC water, and $10 \mu \mathrm{l}$ of SYBR Green II) were conducted twice (Table 2). Further, GAPDH was employed as the reference gene. The thermal program used in the real-time PCR consisted of 95 for $10 \mathrm{~min}, 60$ for $15 \mathrm{~s}$, and 72 for $1 \mathrm{~min}$ (replication of 40 cycles). A melting curve was plotted to investigate the accuracy of the data while a standard diagram was drawn to optimize the experimental conditions. Finally, gene expression of data was calculated using Pfaffl's (2001) method through gene expression in relation with the reference gene [16].

\section{Statistical analysis}

The Kolmogorov-Smirnov test was used to determine the normality of the distribution. All results were expressed as mean \pm standard deviation. In order to analyze the data and to investigate the inconsistencies of
Table 2. Specific primers used in real-time PCR

\begin{tabular}{|c|c|c|c|}
\hline $\begin{array}{l}\text { Gene bank } \\
\text { number }\end{array}$ & $\begin{array}{l}\text { Base } \\
\text { pairs }\end{array}$ & Primer & Name \\
\hline \multirow{2}{*}{ NM_199267.2 } & \multirow{2}{*}{135} & F: 5'-CATACGCTGACCCTAGCCTG-3' & \multirow{2}{*}{$-N F-k \beta$} \\
\hline & & R: 5'-TTCTTCAATCCGGTGGCGA-3' & \\
\hline \multirow{2}{*}{ NM_032077.1 } & \multirow{2}{*}{82} & F: 5'-CCATGACAGGCCCAAGTACA-3' & \multirow{2}{*}{ - PON-1 } \\
\hline & & R: 5'-TGAGAGCTTCTATGCCACAAATG-3' & \\
\hline \multirow{2}{*}{ XM_017592435.1 } & \multirow{2}{*}{92} & F: 5'-GACATGCCGCCTGGAGAAAC-3' & \multirow{2}{*}{ - GAPDH } \\
\hline & & R: 5'-AGCCCAGGATGCCCTTTAGT-3' & \\
\hline
\end{tabular}

the observation amongst different groups, the two-way ANOVA method was used, which was then followed by the LSD post-hoc test. Further, the Pearson correlation test was used to determine the potential relationships between the measured variables. Biochemical data were analyzed using SPSS (PASW) 18 (Inc., Chicago, Illinois, USA) and charts were plotted using Origin 6.1 software.

\section{Results}

The SWT resulted in enhanced PON-1 gene expression $(p=0.002, \mathrm{~F}=11.083)$ (Fig. 1A). However, curcumin had no significant effect on PON-1 gene expression $(p=0.4, \mathrm{~F}=0.899)$. The post-hoc test indicated that PON-1 gene expression was significantly higher in the Eth-SWT $(p=0.01)$ and Eth-SWT + Cur $(p=0.002)$ groups, compared with the Eth-Con group. Furthermore, $\mathrm{PON}-1$ gene expression was significantly higher in the Eth-SWT + Cur group than the Eth-Cur group ( $p=0.05$ ) (Fig. 1). SWT did not result in NF-k $\beta$ gene expression $(p=0.28, \mathrm{~F}=1.187)$, but curcumin led to a significant decrease in NF-k $\beta$ gene expression $(p=0.003, \mathrm{~F}=5.333)$. Interaction of SWT and curcumin also resulted in a significant synergic decrease in NF-k $\beta$ gene expression $(p=0.004, \mathrm{~F}=9.544)$. $\mathrm{NF}-\mathrm{k} \beta$ gene expression was significantly higher in the Eth-Con group than the Eth-Cur $(p=0.001)$ and Eth-SWT ( $p=0.006$ ) groups (Fig. 1B).

Based on the mason trichrome results, the collagen sedimentation rate in the tissues of the ethanol group was significantly higher than in the dextrose group (Fig. 2). In addition, the $\mathrm{H} \& \mathrm{E}$ results showed that hepatocyte death and high cell spaces were more observed in ethanol groups compared with the Dext-Con group. This effect was reduced in the training and curcumin groups. Hepatocytes have vacuolic histoplasts and are seen in some cells without membranes (Fig. 3).

\section{Discussion}

The present study indicated that SWT and curcumin resulted in increased PON-1 gene expression 

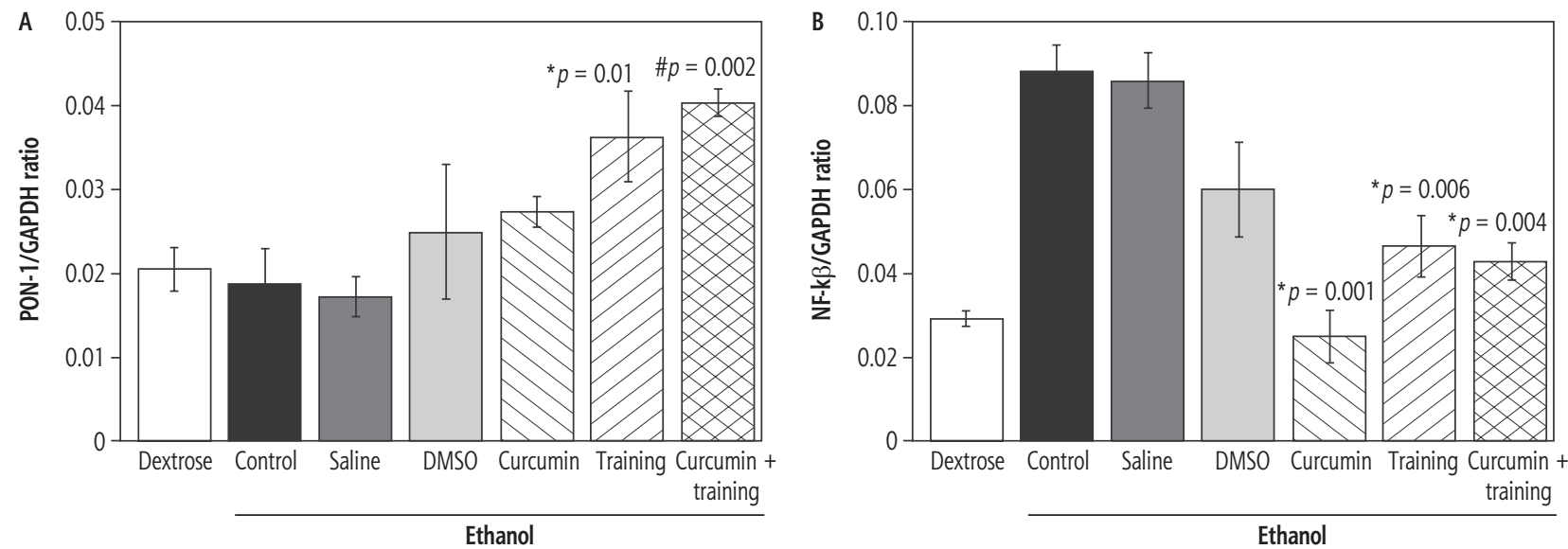

Fig. 1. Changes in liver PON-1 (A) and NF-k $\beta$ (B). * \# Represents significant difference in ethanol-training as well as ethanol-training-curcumin groups compared with ethanol group
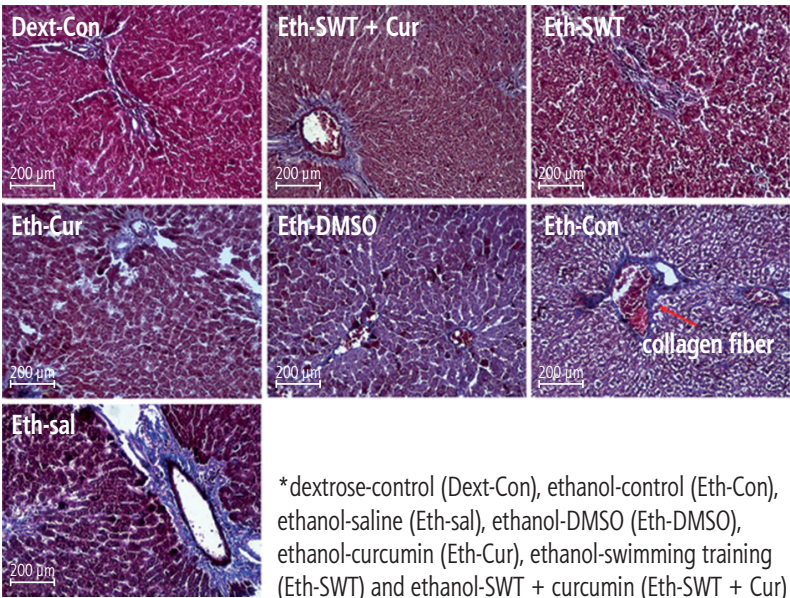

*dextrose-control (Dext-Con), ethanol-control (Eth-Con), ethanol-saline (Eth-sal), ethanol-DMSO (Eth-DMSO), ethanol-curcumin (Eth-Cur), ethanol-swimming training (Eth-SWT) and ethanol-SWT + curcumin (Eth-SWT + Cur)

Fig. 2. Histological examination of the liver tissue by Masson's trichrome staining to evaluate the tissue fibrosis because of increased collagen sedimentation. The collagen sedimentation rate in the tissues of the ethanol group was significantly higher than the dextrose group

and reduced of NF-k $\beta$ gene expression. The variables studied significantly improved in the Eth-SWT group compared with the other groups. Exercise is inherently an oxidative stress factor $[9,17,18]$; therefore, the degree of improvement in the Eth-SWT group was lower than that in the Eth-SWT + Cur group. It is possible that with a longer course of SWT, more improvements should be observed. However, all Eth-SWT, Eth-Cur, and Eth-SWT + Cur groups recorded a significant increase in PON-1 as well as other variables, when compared with the control groups. This can be explained by the fact that curcumin and SWT had a significant synergic effect on PON-1. A subset of the oxidative stress generated by exercise may be inhibited through curcumin. That is probably why the PON-1 improved more in the Eth-SWT + Cur group than in the EthSWT group. In addition, lack of a significant clinical change in the saline and DMSO groups is another
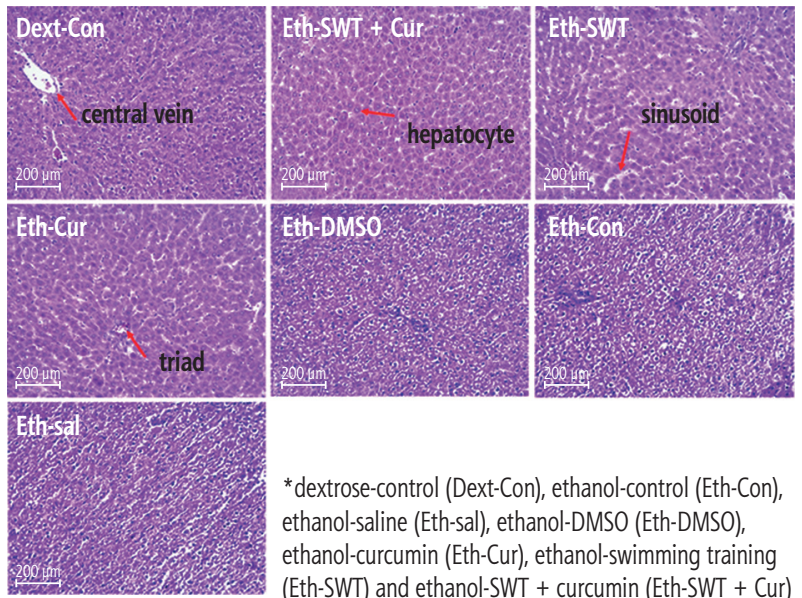

*dextrose-control (Dext-Con), ethanol-control (Eth-Con), ethanol-saline (Eth-sal), ethanol-DMSO (Eth-DMSO), ethanol-curcumin (Eth-Cur), ethanol-swimming training (Eth-SWT) and ethanol-SWT + curcumin (Eth-SWT + Cur)

Fig. 3. Histological examination of the liver tissue by hematoxylin and eosin (H\&E) staining. Hepatocyte death and high cell spaces were more observed in ethanol groups compared with the Dext-Con group

observation suggesting the effectiveness of SWT and curcumin. It is reported that ethanol in rats results in a $25 \%$ reduction in PON-1 activity and a $51 \%$ reduction in PON-1 gene expression [19]. Although some studies have reported elevated PON-1 and HDL-C at moderate ethanol levels [19], there is no conclusive evidence suggesting alcohol consumption could be controlled through the development of a sense of physiological and psychological demands [20, 21]. Additionally, changes in the concentration of anti-inflammatory agents are different from their function [22].

It is likely that the above effects along with protective effects of curcumin resulted in improving liver function. Likewise, synthesis of HDL-C and PON-1 in the liver also increased. Note that in this study, the interactive or independent effect of curcumin and SWT on PON-1 and reduction of NF-k $\beta$ gene expression was mainly observed. Curcumin resulted in the inhibition of inflam- 
matory cytokines of tumor necrosis factor $\alpha$ (TNF- $\alpha$ ), interleukin 6 (IL-6), and oxidative stress in the liver and pancreas of rats and mice. However, it had no effect on improving the tissue pathology $[11,12,23]$. In contrast, it has been reported that curcumin also led to inhibition of oxidative stress and reduction of the NF- $\mathrm{k} \beta$ inflammatory pathway and improvement in the liver tissue $[13,14,24]$. In the present study, observation of some tissue damage in the Eth-Con group can confirm protective effects of curcumin and SWT in other groups.

Factors that have a role in the synthesis of PON-1 are influenced by IL- 6 . The decrease of PON-1 gene expression under inflammatory conditions can be explained by the fact that after one bout of rigorous exercise elevated IL-6 and decreased PON-1 were both observed [25]. The findings of this study indicate that one course of SWT and curcumin interventions elevates PON-1 and inhibits NF- $\mathrm{k} \beta$ gene expression. This may be due to adaptation to the exercise routine, the therapeutic affectability of curcumin, and the diminished complications of the quitting period. Nevertheless, statistical findings confirm the effectiveness of SWT and curcumin, as the control groups did not show any significant clinical changes.

The most important point regarding the relationship between rehabilitation training and increased PON-1 is the adaptation of HDL-C in response to regular exercise. This is because PON-1 is attached to HDL-C. The elevation of HDL-C enhances the probability of increased PON-1. On the other hand, adopting a regular exercise routine leads to the increase in protective and antioxidant factors. In the course of one bout of rigorous exercise, free radicals increase. This increase, through the adaptation through signaling pathways, results in improved antioxidant mechanisms [26]. This finding agrees with the existing research indicating that adults who perform regular exercise have significantly higher PON-1 gene expression [7]. Several factors, such as different types of PON and different types of Apo-proteins, have an effect on PON gene expression. However, since PON-1 is activated in the presence of calcium [27], muscle contractions could affect the activity of this enzyme. In addition, in this study, it was observed that curcumin accelerated the adaptation, as the training period was short.

People who regularly exercise exhibit less oxidative stress in response to one bout of rigorous exercise, which is evident from their higher PON-1 function [79]. Briefly, regular exercise improved antioxidant defense and inhibited low-density lipoprotein (LDL-C) peroxidation. It is worth noting that the antioxidant activity increases in response to regular exercise. In addition, people with better physical training are more likely to recover from the oxidative stress resulting from rigorous exercise $[8,9]$. For example, it has been shown that aerobic training in obese people results in elevated PON-1 and increased leptin and adiponectin $[7,22,28]$. In addition, after six months of aerobic training in obese women, in spite of weight loss, no significant change was observed in HDL-C and PON-1 levels. At the same time, the women's functional indices of HDL-C and PON-1 were improved [29]. Another reason for the lack of consistency in the results is use of animal and human species under different conditions. Whether people or animals had been physically trained plays an important role in the results. The present research is very different in terms of the utilized methods, and this complicates congruence or incongruence of the results with other studies.

Regular exercise resulted in improved response of PON-1 activity immediately after one rigorous exercise bout, which declined after $2 \mathrm{~h}$ and returned to initial levels after $24 \mathrm{~h}$ [9]. These findings confirm that oxidative stress resulting from rigorous exercise causes enhanced LDL-C peroxidation and probably PON-1 activity, which in turn inhibits lipid oxidation [17]. This is because rigorous exercise provides oxidative stress and lipid peroxidation conditions $[9,17]$. One bout of rigorous exercise results in increased antioxidant agents against increased LDL-C peroxidation [18, 25]. It is noteworthy that PON-1 prevents LDL-C oxidation, as described previously.

\section{Limitations}

One of the limitations of this study was the use of a short period of interventions. It was intended to reduce the pain of animals due to the methodology of the study. Also, it was meant to reduce the number of sacrifices, one of the reasons for choosing a small sample size, which can affect the findings of the study. Otherwise, measuring other liver parameters could provide more clear findings. In addition, it has to be remembered that due to the precise control of the experimental procedure, it is difficult to generalize and compare findings with other studies, especially studies on human models.

\section{Conclusions}

The findings of this research suggest that the combination of curcumin and SWT may be used to improve the inflammatory state after binge ethanol drinking. It can be concluded that SWT and curcumin may result in enhanced PON-1 as well as reduced $\mathrm{NF}-\mathrm{k} \beta$ gene expression. Therefore, it is suggested that 
the course of complications in the alcohol quitting period should be shortened, while a combination of curcumin and training is used. Swimming exercises are an appropriate way to rehabilitate via increase floating in the water and weight tolerance, as shown in the present study. In a research study on humans, the intensity of similar exercises should be controlled and documented.

\section{Acknowledgements}

The authors of this paper would like to express their thanks to Histogenotech research center (www.histohene.ir) for their critical comments during the project.

\section{Disclosure}

The authors report no conflict of interest.

\section{References}

1. Mokdad AH, Marks JS, Stroup DF, et al. Actual causes of death in the United States, 2000. JAMA 2004; 291: 1238-1245.

2. Federico A, Cotticelli G, Festi D, et al. The effects of alcohol on gastrointestinal tract, liver and pancreas: evidence-based suggestions for clinical management. Eur Rev Med Pharmacol Sci 2015; 19: 1922-1940.

3. Schroder H, Marrugat J, Fito M, et al. Alcohol consumption is directly associated with circulating oxidized low-density lipoprotein. Free Radic Biol Med 2006; 40: 1474-1481.

4. Jafari M, Leaf DA, Macrae $\mathrm{H}$, et al. The effects of physical exercise on plasma prebeta-1 high-density lipoprotein. Metabolism 2003; 52: 437-442.

5. Leaf DA. The effect of physical exercise on reverse cholesterol transport. Metabolism 2003; 52: 950-957.

6. Shih DM, Xia YR, Wang XP, et al. Combined serum paraoxonase knockout/apolipoprotein E knockout mice exhibit increased lipoprotein oxidation and atherosclerosis. J Biol Chem 2000; 275: 17527-17535.

7. Cakmak A, Zeyrek D, Atas A, et al. Paraoxonase activity in athletic adolescents. Pediatr Exerc Sci 2010; 22: 93-104.

8. Otocka-Kmiecik A, Lewandowski M, Szkudlarek U, et al. Aerobic training modulates the effects of exercise-induced oxidative stress on PON1 activity: a preliminary study. ScientificWorldJournal 2014; 2014: 230271.

9. Tomas M, Elosua R, Senti M, et al. Paraoxonase1-192 polymorphism modulates the effects of regular and acute exercise on paraoxonase1 activity. J Lipid Res 2002; 43: 713-720.

10. Marsillach J, Ferre N, Vila MC, et al. Serum paraoxonase-1 in chronic alcoholics: relationship with liver disease. Clin Biochem 2007; 40: 645-650.

11. Ciftci O, Ozdemir I, Tanyildizi S, et al. Antioxidative effects of curcumin, beta-myrcene and 1,8-cineole against 2,3,7,8-tetrachlorodibenzo-p-dioxin-induced oxidative stress in rats liver. Toxicol Ind Health 2011; 27: 447-453.

12. Wang ME, Chen YC, Chen IS, et al. Curcumin protects against thioacetamide-induced hepatic fibrosis by attenuating the inflammatory response and inducing apoptosis of damaged hepatocytes. J Nutr Biochem 2012; 23: 1352-1366.

13. Nanji AA, Jokelainen K, Tipoe GL, et al. Curcumin prevents alcohol-induced liver disease in rats by inhibiting the expression of NF-kappa B-dependent genes. Am J Physiol Gastrointest Liver Physiol 2003; 284: G321-327.

14. Sun Y, Peng ML. Recent advances in curcumin and its derivatives for treatment of liver diseases. Yao Xue Xue Bao 2014; 49: 1483-1490.

15. Maynard ME, Leasure JL. Exercise enhances hippocampal recovery following binge ethanol exposure. PLoS One 2013; 8: e76644.

16. Pfaffl MW. A new mathematical model for relative quantification in real-time RT-PCR. Nucleic Acids Res 2001; 29: e45.

17. Clarkson PM. Antioxidants and physical performance. Crit Rev Food Sci Nutr 1995; 35: 131-141.

18. Somani SM, Rybak LP. Comparative effects of exercise training on transcription of antioxidant enzyme and the activity in old rat heart. Indian J Physiol Pharmacol 1996; 40: 205-212.

19. Rao MN, Marmillot P, Gong M, et al. Light, but not heavy alcohol drinking, stimulates paraoxonase by upregulating liver mRNA in rats and humans. Metabolism 2003; 52: 1287-1294.

20. de Paiva Lima C, da Silva ESDA, Damasceno S, et al. Loss of control over the ethanol consumption: differential transcriptional regulation in prefrontal cortex. J Neurogenet 2017; 31: 170-177.

21. Kang SY, Kwon OS, Moon JY, et al. Mechanical stimulation of the HT7 acupuncture point to reduce ethanol self-administration in rats. Evid Based Complement Alternat Med 2017; 2017: 6578621 .

22. Casella-Filho A, Chagas AC, Maranhao RC, et al. Effect of exercise training on plasma levels and functional properties of high-density lipoprotein cholesterol in the metabolic syndrome. Am J Cardiol 2011; 107: 1168-1172.

23. Gulcubuk A, Altunatmaz K, Sonmez K, et al. Effects of curcumin on tumour necrosis factor-alpha and interleukin-6 in the late phase of experimental acute pancreatitis. J Vet Med A Physiol Pathol Clin Med 2006; 53: 49-54.

24. Samuhasaneeto S, Thong-Ngam D, Kulaputana O, et al. Curcumin decreased oxidative stress, inhibited NF-kB activation, and improved liver pathology in ethanol-induced liver injury in rats. J Biomed Biotechnol 2009; 2009: 8.

25. Van Lenten BJ, Wagner AC, Navab M, et al. Oxidized phospholipids induce changes in hepatic paraoxonase and ApoJ but not monocyte chemoattractant protein-1 via interleukin-6. J Biol Chem 2001; 276: 1923-1929.

26. Vollaard NB, Shearman JP, Cooper CE. Exercise-induced oxidative stress:myths, realities and physiological relevance. Sports Med 2005; 35: 1045-1062.

27. Primo-Parmo SL, Sorenson RC, Teiber J, et al. The human serum paraoxonase/arylesterase gene (PON1) is one member of a multigene family. Genomics 1996; 33: 498-507.

28. Koncsos P, Seres I, Harangi M, et al. Human paraoxonase-1 activity in childhood obesity and its relation to leptin and adiponectin levels. Pediatr Res 2010; 67: 309-313.

29. Aicher BO, Haser EK, Freeman LA, et al. Diet-induced weight loss in overweight or obese women and changes in high-density lipoprotein levels and function. Obesity 2012; 20: 2057-2062. 